\title{
Modeling the efficiency of microfiltration process in reducing the hardness, improvement the non-sugar component rejection and purity of raw sugar beet juice
}

\author{
Shamim Shahriari ${ }^{1}$, Vahid Hakimzadeh ${ }^{1}$, Mostafa Shahidi ${ }^{2}$ \\ 1 - Department of Food Science and technology, Quchan Branch, Islamic Azad University, Quchan, \\ Iran. \\ 2 - Department of Food Chemistry, Research Institute of Food Science and Technology, Mashhad, \\ Iran
}

\section{Keywords: \\ Sugar beet \\ Microfiltration \\ Neural network \\ Levenberg \\ Tangent}

\section{Article history:}

Received

16.10.2017

Received in

revised form

20.12.2017

Accepted

29.12.2017

\section{Corresponding \\ author:}

Vahid

Hakimzadeh

E-mail:

v.hakimzadeh@

yahoo.com

DOI:

10.24263/2304-

974X-2017-6-4-6

\section{Abstract}

Introduction. The aim of this study is determining the best configuration of artificial neural network, different networks with neuron number varying from 2 to 20 , were designed. Their mean square errors, square normalized errors, absolute errors and correlation coefficients were investigated for different learning rules and transfer functions.

Material and Methods. In this study, the potential of microfiltration process in reduction of hardness, improvement of purity and non-sugar rejection of raw beet juice was modeled with different parameters as temperature $\left(30\right.$ and $\left.60{ }^{\circ} \mathrm{C}\right)$ transmembrane pressure $(1,1.75$ and 2.5 Bar) and time (regular time intervals from 1 to $60 \mathrm{~min}$ ) by artificial neural network (ANN). ANN modeling was carried out by Neurosolution software v6 to determine the best type of transport function, learning rule, and determination of applied percentages for training, validation and testing stages.

Results and discussion. The best neural network was the one hidden layer in Levenberg learning rules with tangent transfer function which included 8 neurons and resulted in maximum correlation coefficient for hardness according to temperature, pressure and time variation. The neural network with one hidden layer including 4 neurons with sigmoid transfer function under Levenberg learning rule had the least error and highest $r$ for purity variation. Finally, the neural network with one hidden layer including 2 neurons, under Levenberg learning rule and tangent transfer function had the lowest error and highest correlation for non-sugar rejection percentage. Modeling was carried out with different percentages of data for training that the best prediction correlation for all parameters (turbidity, purity, non-sugar rejection) obtained when $60 \%$ of the data were used for training, $35 \%$ of them were employed for validation and $5 \%$ of the data were used for testing. The correlation of experimental data with the predicted values of the model obtained, too. According to the obtained models, ANN resulted in data with proper correlation with experimental data of hardness, purity and non-sugar rejection with respective correlation coefficients of $0.987,0.980$ and 0.981 . This study also addressed the model sensitivity to input data. The best model sensitivity of the model for prediction of turbidity, purity and non-sugar rejection was related to time.

Conclusion. The best rule for network training for prediction of hardness, purity and non-sugar rejection was Levenberg rule. The model was able to predict the hardness, purity and non-sugar rejection percentage under different operational models in a way that the modeled data showed high correlation with experimental data. 


\section{Introduction}

In spite of passing through purification stages, purified sugar beet juice still contains undesirable non-sugar compounds which can adversely affect the final quality of the sugar. These undesirable compounds include a wide range of organic and inorganic materials such as amino acids, amides, proteins, minerals and etc. Among them nitrogenized compounds and single-valance cations cause molasses (Djuri, 2004). On the other hand, conventional purification methods have high energy consumption and lack of accurate control on addition of lime and carbon dioxide will result in defects in non-sugar rejection due to destruction of surface adsorption of impurities from calcium carbonate crystals. In this regard, membrane processes are now in the center of the focus due to advantages such as reduction in energy consumption, increase of efficiency, no need for chemicals and feasibility (Gyura, 2005; Ghosh, 2003; balakrishnan, 2000). Membrane processes based on microfiltration pressure driving force has attracted the attention of numerous researchers in the field of sugar production.

First, Lancernon et al analyzed application of a ceramic micro-filter (pore size of 0.110 micron) for sugar cane syrup purification in 1993. Then, in 1994, Domir et al investigated the optimal condition of sugar cane extract filtration and expressed that the increase in pressure and slope transverse flow speed can improve flux. Vern et al. (1997) reported the filtration of sugar cane syrup by a micro-filter with pore size of 01 micron, in a way that the resultants could be directly used for crystallization. Farmani et al. (2007) managed to increase the purity of sugar cane clarifier by 0.87 with the use of microfiltration process.

On the other hand, process modeling can play an important role in process design as they are capable of predicting the system performance. Neural network can model complex nonlinear systems with numerous input and outputs (Delgerange, 1998). Artificial neural network is inspired from human brain and neural network and like that, it includes numerous neurons. Similar to human brain, this network can also learn. In cases with numerous input and outputs, application of ANN can be helpful in modeling the system or obtain a structure of data. So far, various topologies and applications have been presented for ANNs that cover a wide range of topics (Menhaj, 2000). Therefore, researchers pay a specific attention to modeling the membrane processes in different industries. For example, Mascula et al. introduced an empirical model to predict the created cake layer for membrane blockage in ultrafiltration processes. Shahidi et al investigated the potential of nanofiltration in treatment of sugar beet pressing wastewater and then modeled in by ANN. The results showed that a network with one hidden layer including 16 neurons with hyperbolic tangent linear transfer function under Levenberg learning rule can provide a proper correlation between the modeled and experimental data.

In this regard, the present research addressed modeling of microfiltration process in reduction of hardness, non-sugar rejection and improvement of raw sugar beet juice as some of the indices of raw syrup purification by ANN method.

\section{Materials and methods}

\section{Membrane process}

Raw sugar beet juice microfiltration process was carried out by a pilot equipped with ceramic membrane with tubular module (made by Bioken Russia and Milar Khorasan 
Companies). The experiments were carried out at two temperatures of 30 and $60{ }^{\circ} \mathrm{C}$ at three pressure levels (1, 1.75 and 2.5 Barr) and 8 equal time intervals from 1 to 60 min (48 experiments) on variation of hardness, non-sugar rejection and purity of permeated flow [8]. The technical properties of the membrane system are listed in Table 1.

Table 1

Technical properties of microfiltration membrane system for purification of raw sugar beet juice

\begin{tabular}{|c|c|c|c|c|c|c|}
\hline $\begin{array}{c}\text { Membrane } \\
\text { material }\end{array}$ & module & MWCO & $\begin{array}{c}\text { Membrane } \\
\text { effective } \\
\text { area }\end{array}$ & $\begin{array}{c}\mathbf{p H} \\
\text { tolerance }\end{array}$ & $\begin{array}{c}\text { Temperature } \\
\text { tolerance }\end{array}$ & $\begin{array}{c}\text { Maximum } \\
\text { tolerable } \\
\text { pressure }\end{array}$ \\
\hline Ceramic & Tubular & $0.2 \mu \mathrm{m}$ & $0.28 \mathrm{~m}^{2}$ & $1-11$ & $10-95^{\circ} \mathrm{C}$ & $3 \mathrm{Bar}$ \\
\hline
\end{tabular}

\begin{abstract}
Assays 1:

Samples purity was calculated based on their polarimetry and brix values from equation

$$
\text { Purity }=(\mathrm{pol} / \text { Brix }) \times 100
$$

Sample hardness was measured by syrup titration with EDTA solution, at concentration of $0.025 \mathrm{moles} /$ lit, according to ICUMSA method. The process was as follows: first, $50 \mathrm{ml}$ of syrup was mixed with $50 \mathrm{ml}$ distilled water and then $10 \mathrm{ml}$ Buffer solution was added to that. Then it underwent titration at the presence of Eriochrome Black reagent and EDTA till reaching to blue color. In this condition, if $\mathrm{n} \mathrm{ml}$ of EDTA was consumed for each $100 \mathrm{ml}$ of syrup, the hardness based on $\mathrm{CaO}$ could be obtained from equation 2 (ICUMSA,2000):
\end{abstract}

$$
\text { Hardness }=1.002 \times n
$$

To calculate percentage of non-sucrose component rejection the pol and Brix of permeat and feed were measured by substitution in equation 3 (Ghosh, 2003; Balakrishnan, 2000):

$$
\text { Non-sugar rejection }=\left[1-\frac{(\text { Brix }- \text { Pol })_{\text {permeat }}}{(\text { Brix }-P o l)_{\text {feed }}}\right] \times 100
$$

\title{
Artificial neural network modeling
}

ANN modeling was conducted by Neurosolution V6. To investigate and evaluate different networks, the data were randomly classified into three sections; in a way that a percentage of data were used for training, some were used for validation and the other part was employed for network testing. During training process, ANN learnt neuron relationships in each cycle of training in order to reach to the predicted values closer to the desirable output values. To find a network with proper architecture, mean square error (MSE), mean absolute error (MAE) and correlation coefficient (R2) were used. Correlation coefficient varies from -1 to 1 . The farther from 0 , the more serious the alignment or opposition of the two investigated parameters will be (Razavi, 2003). 
First, all the test data (48) were randomized; then network structure with one hidden layer and different number of neurons under Levenberg learning rules and momentum and two functions of tangent and Sigmoid, were examined. Moreover, the best data percentage for training, validation and testing of this network were determined and finally the sensitivity of purity variation, hardness and non-sugar rejection to temperature, time and pressure was assessed. For model validation, the correlation between the predicted and experimental data was also calculated (Shahidi, 2012).

\section{Results and discussion}

To find the best configuration of artificial neural network, different networks with neuron number varying from 2 to 20, were designed. Their mean square errors, mean square normalized errors, mean absolute errors and correlation coefficients were investigated for different learning rules and functions as shown in Tables 2 to 4 . In continue the best percentage for training, validation and test with minimum error and maximum correlation coefficient were examined. As Table 2 suggests, the best neural network was the one with one hidden layer in Levenberg learning rules with tangent transfer function which included 8 neurons and resulted in maximum correlation coefficient for hardness according to temperature, pressure and time variation.

Table 2

Different architectures of ANN with different neurons in the hidden layer and transfer functions in the hidden and output layers used for permeate hardness in sugar beet juice microfiltration

\begin{tabular}{|c|c|c|c|c|c|c|c|c|}
\hline Hardness & \multicolumn{9}{|c|}{ Sigmoid } & \multicolumn{4}{c|}{ Tanh } \\
\hline $\begin{array}{c}\text { No of } \\
\text { neurons }\end{array}$ & \multicolumn{9}{|c|}{ MSE } & NMSE & MAE & R & MSE & NMSE & MAE & R \\
\hline 2 & 3.632 & 0.444 & 1.671 & 0.808 & 3.188 & 0.390 & 1.587 & 0.843 \\
\hline 3 & 3.803 & 0.465 & 1.660 & 0.790 & 1.003 & 0.122 & 0.827 & 0.956 \\
\hline 4 & 1.254 & 0.153 & 0.976 & 0.930 & 0.331 & 0.040 & 0.429 & 0.989 \\
\hline 5 & 0.600 & 0.073 & 0.687 & 0.978 & 0.340 & 0.041 & 0.488 & 0.986 \\
\hline 6 & 0.853 & 0.104 & 0.615 & 0.958 & 0.561 & 0.052 & 0.910 & 0.974 \\
\hline 7 & 0.554 & 0.067 & 0.686 & 0.982 & 0.229 & 0.028 & 0.455 & 0.993 \\
\hline $\mathbf{8}$ & 0.576 & 0.070 & 0.662 & 0.979 & $\mathbf{0 . 1 5 8}$ & $\mathbf{0 . 0 1 9}$ & $\mathbf{0 . 3 3 4}$ & $\mathbf{0 . 9 9 3}$ \\
\hline 9 & 0.527 & 0.064 & 0.601 & 0.978 & 0.399 & 0.048 & 0.564 & 0.985 \\
\hline 10 & 0.619 & 0.075 & 0.616 & 0.970 & 0.529 & 0.064 & 0.621 & 0.990 \\
\hline 11 & 0.473 & 0.023 & 0.543 & 0.990 & 0.357 & 0.043 & 0.493 & 0.984 \\
\hline 12 & 0.571 & 0.069 & 0.584 & 0.968 & 0.215 & 0.026 & 0.399 & 0.988 \\
\hline 13 & 0.565 & 0.069 & 0.599 & 0.972 & 0.233 & 0.028 & 0.435 & 0.988 \\
\hline 14 & 0.487 & 0.059 & 0.652 & 0.989 & 0.258 & 0.031 & 0.438 & 0.988 \\
\hline 15 & 0.601 & 0.073 & 0.708 & 0.982 & 0.311 & 0.038 & 0.518 & 0.992 \\
\hline 16 & 0.559 & 0.068 & 0.594 & 0.971 & 0.280 & 0.034 & 0.468 & 0.985 \\
\hline 17 & 0.379 & 0.046 & 0.506 & 0.981 & 0.370 & 0.045 & 0.535 & 0.980 \\
\hline 18 & 0.446 & 0.054 & 0.511 & 0.974 & 0.169 & 0.020 & 0.333 & 0.991 \\
\hline 19 & 1.175 & 0.143 & 0.806 & 0.942 & 0.227 & 0.027 & 0.408 & 0.993 \\
\hline 20 & 0.323 & 0.039 & 0.486 & 0.988 & 0.194 & 0.023 & 0.383 & 0.992 \\
\hline
\end{tabular}


As Table 3 shows, the neural network with one hidden layer including 4 neurons with sigmoid transfer function under Levenberg learning rule had the least error and highest $r$ for purity variation.

Table 3

Different architectures of ANN with different neurons in the hidden layer and transfer functions in the hidden and output layers used for permeate purity in sugar beet juice microfiltration

\begin{tabular}{|c|c|c|c|c|c|c|c|c|}
\hline \multirow{3}{*}{$\begin{array}{c}\text { Purity } \\
\text { No of } \\
\text { neurons }\end{array}$} & \multicolumn{8}{|c|}{ Levenberg } \\
\hline & \multicolumn{4}{|c|}{ Sigmoid } & \multicolumn{4}{|c|}{ Tanh } \\
\hline & MSE & NMSE & MAE & $\mathbf{R}$ & MSE & NMSE & MAE & $\mathbf{R}$ \\
\hline 2 & 0.018 & 0.134 & 0.115 & 0.955 & 0.169 & 0.126 & 0.091 & 0.956 \\
\hline 3 & 0.036 & 0.269 & 0.137 & 0.893 & 0.016 & 0.123 & 0.100 & 0.978 \\
\hline 4 & 0.004 & 0.031 & $\mathbf{0 . 0 5 7}$ & 0.990 & 0.009 & 0.746 & 0.083 & 0.0978 \\
\hline 5 & 0.011 & 0.081 & 0.088 & 0.990 & 0.011 & 0.084 & 0.081 & 0.979 \\
\hline 6 & 0.008 & 0.060 & 0.075 & 0.987 & 0.006 & 0.050 & 0.077 & 0.989 \\
\hline 7 & 0.010 & 0.076 & 0.084 & 0.972 & 0.007 & 0.056 & 0.073 & 0.984 \\
\hline 8 & 0.005 & 0.043 & 0.062 & 0.981 & 0.018 & 0.137 & 0.091 & 0.961 \\
\hline 9 & 0.007 & 0.057 & 0.077 & 0.987 & 0.008 & 0.064 & 0.072 & 0.981 \\
\hline 10 & 0.015 & 0.112 & 0.106 & 0.982 & 0.003 & 0.026 & 0.043 & 0.989 \\
\hline 11 & 0.003 & 0.026 & 0.045 & 0.988 & 0.004 & 0.036 & 0.064 & 0.985 \\
\hline 12 & 0.010 & 0.080 & 0.086 & 0.983 & 0.003 & 0.029 & 0.042 & 0.986 \\
\hline 13 & 0.007 & 0.058 & 0.073 & 0.984 & 0.004 & 0.035 & 0.051 & 0.983 \\
\hline 14 & 0.020 & 0.156 & 0.098 & 0.970 & 0.006 & 0.047 & 0.065 & 0.984 \\
\hline 15 & 0.006 & 0.046 & 0.067 & 0.983 & 0.005 & 0.041 & 0.056 & 0.979 \\
\hline 16 & 0.009 & 0.069 & 0.084 & 0.988 & 0.005 & 0.038 & 0.056 & 0.981 \\
\hline 17 & 0.14 & 0.107 & 0.100 & 0.980 & 0.003 & 0.025 & 0.047 & 0.988 \\
\hline 18 & 0.005 & 0.038 & 0.060 & 0.981 & 0.011 & 0.086 & 0.081 & 0.980 \\
\hline 19 & 0.008 & 0.067 & 0.076 & 0.973 & 0.006 & 0.044 & 0.048 & 0.978 \\
\hline 20 & 0.007 & 0.059 & 0.076 & 0.985 & 0.004 & 0.032 & 0.046 & 0.983 \\
\hline
\end{tabular}

Finally, the neural network with one hidden layer (including 2 neurons), under Levenberg learning rule and tangent transfer function had the lowest error and highest correlation for non-sugar rejection percentage.

As it can be seen in Table 5, a comparison was made between momentum and Levenberg learning rules in terms of presenting the best transfer function with minimum error and maximum correlation for hardness, purity and non-sugar rejection. 
Table 4

Different architectures of ANN with different neurons in the hidden layer and transfer functions in the hidden and output layers used for Non-sugar rejection in sugar beet juice microfiltration

\begin{tabular}{|c|c|c|c|c|c|c|c|c|}
\hline $\begin{array}{c}\text { Non } \\
\text { sugar } \\
\text { rejection }\end{array}$ & \multicolumn{8}{|c|}{ Levenberg } \\
\hline \multirow{2}{*}{$\begin{array}{c}\text { No of } \\
\text { neurons }\end{array}$} & \multicolumn{4}{|c|}{ sigmoid } & \multicolumn{4}{|c|}{ Tanh } \\
\hline & MSE & NMSE & MAE & $\mathbf{r}$ & MSE & NMSE & MAE & $\mathbf{R}$ \\
\hline 2 & 1.205 & 0.059 & 0.860 & 0.981 & 0.419 & 0.20 & 0.514 & 0.993 \\
\hline 3 & 1.270 & 0.063 & 0.974 & 0.984 & 1.132 & 0.056 & 0.929 & 0.978 \\
\hline 4 & 0.476 & 0.024 & 0.600 & 0.990 & 1.382 & 0.068 & 0.939 & 0.965 \\
\hline 5 & 1.677 & 0.083 & 1.020 & 0.959 & 0.826 & 0.041 & 0.718 & 0.979 \\
\hline 6 & 0.34 & 0.036 & 0.670 & 0.982 & 1.059 & 0.052 & 0.910 & 0.974 \\
\hline 7 & 1.183 & 0.058 & 1.001 & 0.972 & 0.367 & 0.018 & 0.484 & 0.992 \\
\hline 8 & 1.096 & 0.054 & 0.893 & 0.974 & 0.704 & 0.035 & 0.566 & 0.983 \\
\hline 9 & 0.784 & 0.039 & 0.668 & 0.980 & 0.620 & 0.030 & 0.620 & 0.984 \\
\hline 10 & 0.661 & 0.032 & 0.679 & 0.984 & 0.720 & 0.035 & 0.591 & 0.987 \\
\hline 11 & 0.468 & 0.023 & 0.543 & 0.990 & 0.499 & 0.024 & 0.562 & 0.988 \\
\hline 12 & 0.824 & 0.041 & 0.780 & 0.979 & 0.356 & 0.017 & 0.376 & 0.991 \\
\hline 13 & 0.963 & 0.047 & 0.806 & 0.975 & 0.342 & 0.017 & 0.430 & 0.977 \\
\hline 14 & 0.732 & 0.036 & 0.584 & 0.983 & 0.501 & 0.024 & 0.532 & 0.989 \\
\hline 15 & 0.645 & 0.032 & 0.643 & 0.984 & 0.580 & 0.028 & 0.606 & 0.989 \\
\hline 16 & 0.679 & 0.033 & 0.689 & 0.983 & 0.404 & 0.020 & 0.439 & 0.992 \\
\hline 17 & 0.792 & 0.039 & 0.739 & 0.980 & 0.458 & 0.022 & 0.528 & 0.989 \\
\hline 18 & 0.982 & 0.048 & 0.826 & 0.980 & 0.633 & 0.031 & 0.610 & 0.985 \\
\hline 19 & 0.639 & 0.031 & 0.608 & 0.984 & 0.438 & 0.021 & 0.450 & 0.991 \\
\hline 20 & 0.774 & 0.038 & 0.742 & 0.980 & 0.422 & 0.021 & 0.489 & 0.992 \\
\hline
\end{tabular}

Table 5

Comparison of two learning rules used for selected ANN architectures to permeate Hardness, purity and non-sugar rejection in sugar beet juice microfiltration

\begin{tabular}{|c|c|c|c|c|c|c|c|c|c|c|c|c|}
\hline \multicolumn{6}{|c|}{ Momentum } & \multicolumn{6}{|c|}{ Levenberg } & \multirow[b]{2}{*}{ 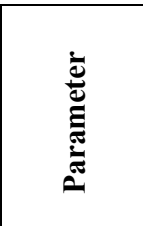 } \\
\hline$=$ & $\sum^{5}$ &  & $\sum_{\sum}^{\frac{1}{2}}$ & 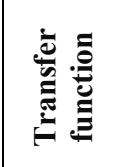 & 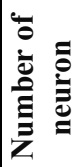 & $=$ & $\sum^{5}$ & $\sum_{Z}^{\frac{5}{n}}$ & $\sum^{\sqrt[5]{2}}$ & 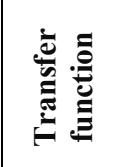 &  & \\
\hline 0.935 & 0.808 & 0.132 & 1.083 & Tangent & 20 & 0.993 & 0.334 & 0.019 & 0.158 & \begin{tabular}{|l|} 
Tangent \\
\end{tabular} & 8 & $\mathrm{Ha}$ \\
\hline 0.985 & 0.093 & 0.085 & 0.011 & Tangent & 18 & 0.990 & 0.057 & 0.031 & 0.004 & sigmoid & 4 & purity \\
\hline 0.969 & 0.998 & 0.066 & 1.324 & Tangent & 19 & 0.993 & 0.514 & 0.020 & 0.419 & Tangent & 2 & $\begin{array}{l}\text { Non sugar } \\
\text { Rejection }\end{array}$ \\
\hline
\end{tabular}




\section{Proper percentages for training, validation and testing}

Modeling was carried out with different percentages of data for training, validation and testing. For this purpose, first the best percentage of data for training was selected according to correlation coefficient. Based on that, the best data percentage for validation and testing were selected as shown in Tables 6-8.

Table 6

Comparison of different percentages of data used for training of selected ANN architectures to model the permeate hardness

\begin{tabular}{|c|c|c|c|c|c|c|}
\hline $\begin{array}{c}\text { Training } \\
\text { Data (\%) }\end{array}$ & $\begin{array}{c}\text { Validation } \\
\text { Data (\%) }\end{array}$ & $\begin{array}{c}\text { Testing } \\
\text { Data (\%) }\end{array}$ & MSE & NMSE & MAE & R \\
\hline 5 & 47.5 & 47.5 & 20.496 & 1.279 & 3.493 & 0.560 \\
\hline 10 & 45.0 & 45.0 & 22.165 & 1.451 & 3.698 & 0.619 \\
\hline 15 & 42.5 & 42.5 & 17.391 & 0.980 & 3.384 & 0.503 \\
\hline 20 & 40.0 & 40.0 & 8.058 & 0.577 & 2.416 & 0.802 \\
\hline 25 & 37.5 & 37.5 & 2.163 & 0.212 & 0.999 & 0.919 \\
\hline 30 & 35.0 & 35.0 & 0.733 & 0.040 & 0.715 & 0.981 \\
\hline 35 & 32.5 & 32.5 & 1.044 & 0.092 & 0.836 & 0.978 \\
\hline 40 & 30.0 & 30.0 & 2.785 & 0.305 & 1.298 & 0.837 \\
\hline 45 & 27.5 & 27.5 & 1.120 & 0.106 & 0.810 & 0.974 \\
\hline 50 & 25.0 & 25.0 & 0.577 & 0.035 & 0.595 & 0.991 \\
\hline 55 & 22.5 & 22.5 & 0.158 & 0.016 & 0.365 & 0.992 \\
\hline 60 & 20.0 & 20.0 & 0.158 & 0.019 & 0.334 & 0.993 \\
\hline
\end{tabular}

Table 7

Comparison of different percentages of data used for training of selected ANN architectures to model the permeate purity

\begin{tabular}{|c|c|c|c|c|c|c|}
\hline $\begin{array}{c}\text { Training } \\
\text { Data } \\
(\%)\end{array}$ & $\begin{array}{c}\text { Validation } \\
\text { Data (\%) }\end{array}$ & $\begin{array}{c}\text { Testing } \\
\text { Data (\%) }\end{array}$ & MSE & NMSE & MAE & R \\
\hline 5 & 47.5 & 47.5 & 0.680 & 2.325 & 0.648 & 0.354 \\
\hline 10 & 45.0 & 45.0 & 0.227 & 0.601 & 0.344 & 0.734 \\
\hline 15 & 42.5 & 42.5 & 0.101 & 0.406 & 0.225 & 0.857 \\
\hline 20 & 40.0 & 40.0 & 0.225 & 2.830 & 0.401 & 0.789 \\
\hline 25 & 37.5 & 37.5 & 0.047 & 0.301 & 0.188 & 0.908 \\
\hline 30 & 35.0 & 35.0 & 0.018 & 0.089 & 0.109 & 0.961 \\
\hline 35 & 32.5 & 32.5 & 0.031 & 0.087 & 0.150 & 0.971 \\
\hline 40 & 30.0 & 30.0 & 0.102 & 0.380 & 0.228 & 0.916 \\
\hline 45 & 27.5 & 27.5 & 0.017 & 0.061 & 0.087 & 0.984 \\
\hline 50 & 25.0 & 25.0 & 0.029 & 0.065 & 0.119 & 0.982 \\
\hline 55 & 22.5 & 22.5 & 0.008 & 0.026 & 0.080 & 0.989 \\
\hline $\mathbf{6 0}$ & $\mathbf{2 0 . 0}$ & $\mathbf{2 0 . 0}$ & $\mathbf{0 . 0 0 4}$ & $\mathbf{0 . 0 3 1}$ & $\mathbf{0 . 0 5 7}$ & $\mathbf{0 . 9 9 0}$ \\
\hline
\end{tabular}


Table 8

Comparison of different percentages of data used for training of selected ANN architectures to model the non-sugar rejection

\begin{tabular}{|c|c|c|c|c|c|c|}
\hline $\begin{array}{c}\text { Training } \\
\text { Data (\%) }\end{array}$ & $\begin{array}{c}\text { Validation } \\
\text { Data (\%) }\end{array}$ & $\begin{array}{c}\text { Testing } \\
\text { Data (\%) }\end{array}$ & MSE & NMSE & MAE & R \\
\hline 5 & 47.5 & 47.5 & 25.616 & 0.907 & 4.156 & 0.874 \\
\hline 10 & 45.0 & 45.0 & 10.524 & 0.523 & 2.846 & 18.181 \\
\hline 15 & 42.5 & 42.5 & 1.562 & 0.076 & 1.090 & 0.961 \\
\hline 20 & 40.0 & 40.0 & 7.202 & 0.366 & 1.770 & 0.822 \\
\hline 25 & 37.5 & 37.5 & 11.941 & 0.917 & 2.091 & 77.777 \\
\hline 30 & 35.0 & 35.0 & 2.326 & 0.090 & 1.190 & 0.963 \\
\hline 35 & 32.5 & 32.5 & 3.136 & 0.148 & 1.441 & 0.925 \\
\hline 40 & 30.0 & 30.0 & 0.711 & 0.034 & 0.690 & 0.983 \\
\hline 45 & 27.5 & 27.5 & 0.903 & 0.039 & 0.788 & 0.982 \\
\hline 50 & 25.0 & 25.0 & 1.429 & 0.051 & 1.056 & 0.981 \\
\hline 55 & 22.5 & 22.5 & 0.848 & 0.043 & 0.710 & 0.989 \\
\hline $\mathbf{6 0}$ & $\mathbf{2 0 . 0}$ & $\mathbf{2 0 . 0}$ & $\mathbf{0 . 4 6 8}$ & $\mathbf{0 . 0 2 3}$ & $\mathbf{0 . 5 4 3}$ & $\mathbf{0 . 9 9 0}$ \\
\hline
\end{tabular}

As mentioned before, after determination of the best data percentages for network training, proper percentages were examined for validation and testing as presented in Tables 9-11.

Table9

Comparison of different percentages of data used for cross validation and testing of selected ANN architectures to model the permeate hardness

\begin{tabular}{|c|c|c|c|c|c|c|}
\hline $\begin{array}{c}\text { Training } \\
\text { Data (\%) }\end{array}$ & $\begin{array}{c}\text { Validation } \\
\text { Data (\%) }\end{array}$ & $\begin{array}{c}\text { Testing } \\
\text { Data (\%) }\end{array}$ & MSE & NMSE & MAE & R \\
\hline 60 & 5 & 35 & 0.324 & 0.021 & 0.419 & 0.989 \\
\hline 60 & 10 & 30 & 3.738 & 0.205 & 1.306 & 0.936 \\
\hline 60 & 15 & 25 & 0.810 & 0.081 & 0.760 & 0.960 \\
\hline 60 & 20 & 20 & 0.424 & 0.028 & 0.451 & 0.989 \\
\hline 60 & 25 & 15 & 0.515 & 0.026 & 0.485 & 0.994 \\
\hline 60 & 30 & 10 & 0.219 & 0.030 & 0.359 & 0.985 \\
\hline $\mathbf{6 0}$ & $\mathbf{3 5}$ & $\mathbf{5}$ & $\mathbf{0 . 5 6 5}$ & $\mathbf{0 . 2 1 3}$ & $\mathbf{0 . 6 9 9}$ & $\mathbf{1}$ \\
\hline
\end{tabular}


Table10

Comparison of different percentages of data used for cross validation and testing of selected ANN architectures to model the permeate purity

\begin{tabular}{|c|c|c|c|c|c|c|}
\hline $\begin{array}{c}\text { Training } \\
\text { Data (\%) }\end{array}$ & $\begin{array}{c}\text { Validation } \\
\text { Data (\%) }\end{array}$ & $\begin{array}{c}\text { Testing } \\
\text { Data (\%) }\end{array}$ & MSE & NMSE & MAE & R \\
\hline 60 & 5 & 35 & 0.043 & 0.184 & 0.163 & 0.936 \\
\hline 60 & 10 & 30 & 0.007 & 0.042 & 0.073 & 0.979 \\
\hline 60 & 15 & 25 & 0.006 & 0.045 & 0.071 & 0.984 \\
\hline 60 & 20 & 20 & 0.011 & 0.050 & 0.097 & 0.979 \\
\hline 60 & 25 & 15 & 0.032 & 0.067 & 0.112 & 0.981 \\
\hline 60 & 30 & 10 & 0.005 & 0.023 & 0.070 & 0.933 \\
\hline $\mathbf{6 0}$ & $\mathbf{3 5}$ & $\mathbf{5}$ & $\mathbf{0 . 0 1 5}$ & $\mathbf{0 . 3 0 3}$ & $\mathbf{0 . 1 1 8}$ & $\mathbf{1}$ \\
\hline
\end{tabular}

Table11

Comparison of different percentages of data used for cross validation and testing of selected ANN architectures to model the non-sugar rejection

\begin{tabular}{|c|c|c|c|c|c|c|}
\hline $\begin{array}{c}\text { Training } \\
\text { Data (\%) }\end{array}$ & $\begin{array}{c}\text { Validation } \\
\text { Data (\%) }\end{array}$ & $\begin{array}{c}\text { Testing } \\
\text { Data (\%) }\end{array}$ & MSE & NMSE & MAE & R \\
\hline 60 & 5 & 35 & 1.063 & 0.066 & 0.884 & 0.986 \\
\hline 60 & 10 & 30 & 1.346 & 0.069 & 0.874 & 0.967 \\
\hline 60 & 15 & 25 & 0.763 & 0.034 & 0.565 & 0.984 \\
\hline 60 & 20 & 20 & 0.734 & 0.028 & 0.728 & 0.991 \\
\hline 60 & 25 & 15 & 0.512 & 0.089 & 0.566 & 0.962 \\
\hline 60 & 30 & 10 & 0.550 & 0.026 & 0.621 & 0.996 \\
\hline $\mathbf{6 0}$ & $\mathbf{3 5}$ & $\mathbf{5}$ & $\mathbf{0 . 2 2 5}$ & $\mathbf{0 . 2 0 4}$ & $\mathbf{0 . 3 6 3}$ & $\mathbf{1}$ \\
\hline
\end{tabular}

As seen in Tables 6-11, the best prediction correlation for all parameters (turbidity, purity, non-sugar rejection) obtained when $60 \%$ of the data were used for training, $35 \%$ of them were employed for validation and $5 \%$ of the data were used for testing.

\section{Correlation between the tested vales and experimental data}

Figure 1 shows the correlation of experimental data with the predicted values of the model. According to the obtained models, ANN resulted in data with proper correlation with experimental data of hardness, purity and non-sugar rejection with respective correlation coefficients of $0.987,0.980$ and 0.981 . 

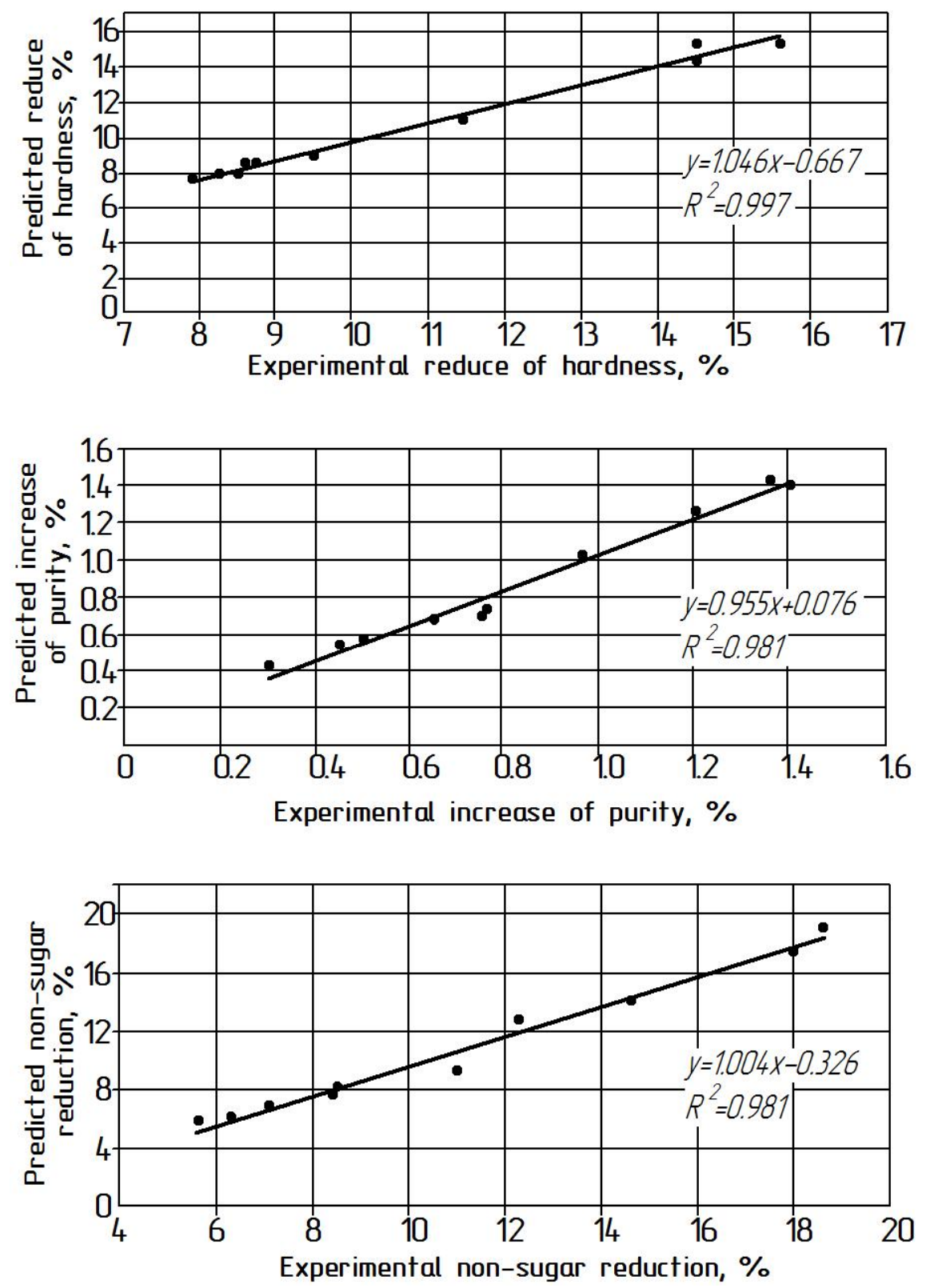

Figure 1. Correlation of the experimental data with the predicted values

\section{Sensitivity of the model to input data}

This study also addressed the model sensitivity to input data. As Figure 2 demonstrated, the best model sensitivity of the model for prediction of turbidity, purity and non-sugar rejection was related to time. 


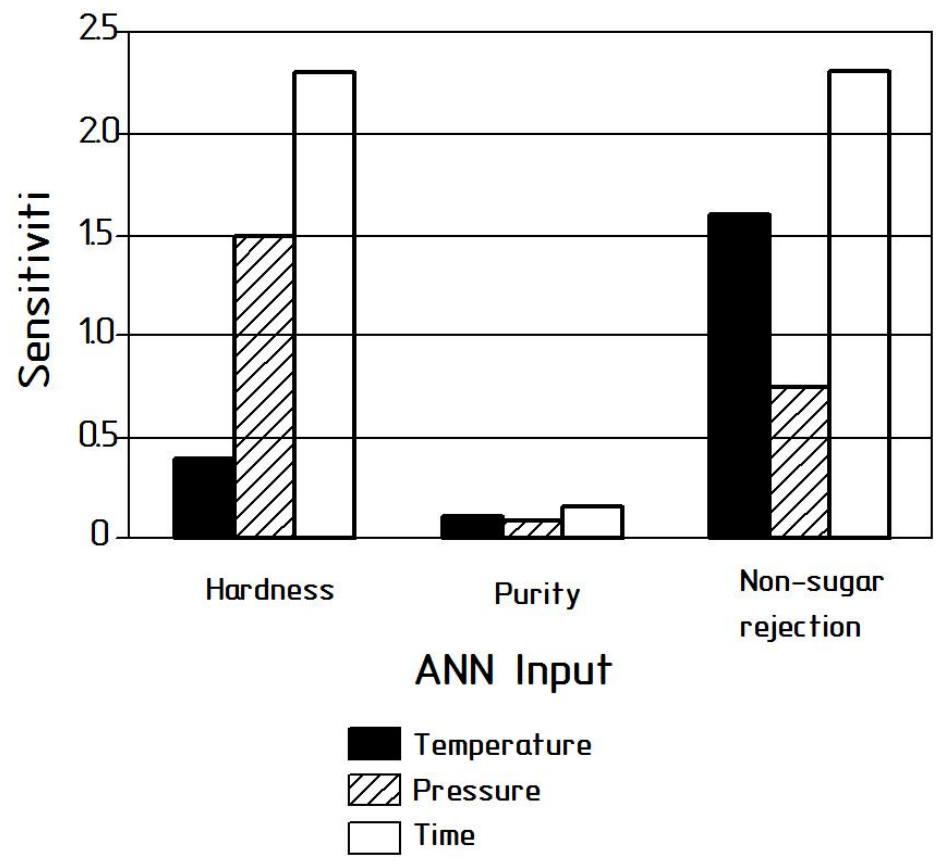

Figure 2. Models' sensitivity to prediction of flux, color and turbidity

\section{Conclusion}

Results of modeling microfiltration process in raw beet juice purification showed that the best rule for network training for prediction of hardness, purity and non-sugar rejection was Levenberg rule. The best data percentages for training, validation and testing were $60 \%, 35 \%$ and $5 \%$, respectively. the model was able to predict the hardness, purity and non-sugar rejection percentage under different operational models in a way that the modeled data showed high correlation with experimental data (Table 12).

Table 12

Summarized result of modeling of hardness, purity and non-sugar rejection changes in purification of raw beet juice by microfiltration

\begin{tabular}{|c|c|c|c|c|c|c|}
\hline $\begin{array}{c}\text { Correlation } \\
\text { coefficient }\end{array}$ & $\begin{array}{c}\text { Percentage } \\
\text { of learning/ } \\
\text { validation/ } \\
\text { test }\end{array}$ & $\begin{array}{c}\text { Learning } \\
\text { rule }\end{array}$ & $\begin{array}{c}\text { Transfer } \\
\text { function }\end{array}$ & $\begin{array}{c}\text { Number } \\
\text { of } \\
\text { neuron }\end{array}$ & $\begin{array}{c}\text { Hidden } \\
\text { layer }\end{array}$ & $\begin{array}{c}\text { Dependent } \\
\text { variable }\end{array}$ \\
\hline 1 & $60 / 35 / 5$ & Levenberge & Tangent & 8 & 1 & Hardness \\
\hline 1 & $60 / 35 / 5$ & Levenberge & Sigmoid & 4 & 1 & Purity \\
\hline 1 & $60 / 35 / 5$ & Levenberge & Tangent & 2 & 1 & $\begin{array}{c}\text { Non sugar } \\
\text { rejection }\end{array}$ \\
\hline
\end{tabular}




\section{- Food Technology}

\section{References}

1. Balakrishnan M., Dau M. and Bhagat J. (2000), Ultrafiltration for juice purification in plantation white sugar manufacture, International Sugar Journal, 102, pp. 21-25.

2. Bubnik Z., Hinkova A and P. Kadlec. (1998), Crossflow micro- and ultrafiltration applied on ceramic membranes in impure sugar solutions, Czech. J. Food Sci., 16(1), pp. 29-34.

3. Domier M., Decloux M., Lebert A., Trystram G. (1997), Use of experimental design to establish optimal cross-flow filtration condition, J. Food process Eng., 17, pp. 73-92.

4. Delgrange N., Cabassud C., Cabassud M., Durand-Bourlier L. and Lain J.M. (1998), Neural network for prediction of ultrafiltration transmembrane pressure application to drink water, Journal of Membrane Science, 150, pp. 111-123.

5. Djuri M, Gyura J., Zavargo Z. (2004), The analysis of process variables influencing some characteristics of permeate from ultraand nanofiltration in sugar beet processing, Desalination, 169 , pp. 167-183

6. Farmani B. M. H., Haddad Khodaparast M. H., Hesari J., and Aharizad S. (2007), Effect of using from ceramic micro-filtration on purity, turbidity and color of sugarcane juice, Iranina food science and technology research journal, 2(2), pp. 4552.

7. Ghosh A.M., and Balakrishnan M. (2003), Pilot demonstration of sugarcane juice ultrafiltration in an India sugar factory, Journal of Food Engineering, 58, pp. 143-150.

8. Gyura J., Šereš Z., Eszterle M., (2005), Influence of operating parameters on separation of green syrup colored matter from sugar beet by ultra- and nanofiltration, Journal of Food Engineering, 66, pp. 89-96.

9. Hakimzadeh V., Razavi S.M.A., Pirouzifard M.K. (2006), The potential of microfiltration and ultrafiltration process in purification of raw sugar beet juice, Desalination, 200, pp. 520-522.

10. Hanssens T.R., Vannispen J.G.M., Koerts K. and Nie L.H.de. (1984), Ultrafiltration an alternative for raw juice purification in the beet sugar industry, Zukerind, 109, pp. 1624.

11. Hinkova A., Bubnik Z., Kadlec P. and Pridal J. (2002), Potentials of separation membranes in the sugar industry, Separation and Purification Technology, 26, pp. 101-110.

12. ICUMSA (2000), The determination of calcium in sugar products by EDTA titration, Method GS8/2/3/4-9.

13. Lancrenon X., Kientz G. (1993), Mineral memberanes for sugar industry, Sugar y azucar, 88, pp. 39-45.

14. Masciola D. A., Viadero R.C, and Reed B.E. (2001), UF flux prediction for oil-inwater emulsions: Anal Series Resistance, J. Membrane Sci., pp. 184-197.

15. Menhaj M.B. (2000), Fundamental of neural networks, Computational illteligence, 1.

16. Misra S.N., Balakrishnan M. and Ghosh A.M. (2000), Improvement in clarified juice characteristics through ultrafiltration, Proc. S.T.A.I., 62, pp. 28-36.

17. Razavi S.M.A., Mousavi S.M, and Mortazavi S.A. (2003), Dynamic prediction of milk ultrafiltration performance: a neural network approach, Chem. Eng. Sci., 58, pp. 41854195.

18. Shahidi Noghabi M., Razavi S.M.A, and Mousavi S. M. (2012), Prediction of permeate flux and ionic compounds rejection of sugar beet press water nanofiltration using artificial neural networks, Desalination and Water Treatment, 44(1-3), pp. 83-91. 
19. Vercelloti J. R., Clarke M.A., Godshall M. A., Blanco S., Patout W.S, and Florence R.A. (1998), Chemistry of membrane separation process in sugar industry applications, Zuckerind, 123, pp. 736-745.

20. Vern C. (1995), The beet sugar factory in the future, Int. Sugar J., 97, pp. 310-314. 